\title{
Rheological properties of rammed clay from illitic clay in relation to the amount of illite
}

\author{
Pavel Padevět ${ }^{1, *}$, Petr Bittnar ${ }^{1}$, and Barbora Mužíková ${ }^{1}$ \\ ${ }^{1} \mathrm{CTU}$ in Prague,Faculty of Civil Engineering, Thákurova 7, 166 29, Prague 6, Czech Republic
}

\begin{abstract}
The paper deals with the rheological properties of rammed unfired clay prepared from illitic clay. Rammed earth contains filler, binder and water. The materials were compared with the amount of filler 20 and $30 \%$ of the total weight of the mixture. The amount of water and clay affects the creep and shrinkage of the produced material. Creep properties are compared at the end of the article.
\end{abstract}

\section{Introduction}

The design of building structures depends on the investor's idea and many technical parameters. Material properties are among the important bases for the calculation of building structures [1,2]. Important material properties are compressive and tensile strengths, modulus of elasticity, Poisson coefficient, as well as rheological properties.

The rheological properties, which are important for blown clay, are creep and shrinkage. These properties play a very important role because unburnt clay is not reinforced by firing clay.

The basic kind of clays, which are usable for buildings, are illitic, illitic-kaolinitic and montmorillonite clay [3]. These clays differ greatly in their properties [4]. The difference is influenced by the different structure of the clays themselves [5]. This work is focused on comparison of rheological properties of illitic clay see Fig.1.

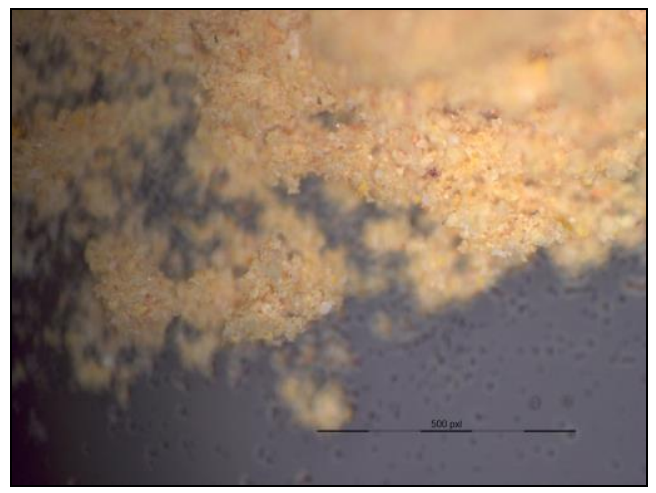

Fig. 1. Illitic clay under view of optical microscope, optical magnification 50x.

\footnotetext{
* Corresponding author: pavel.padevet@fsv.cvut.cz
} 


\section{Material and its preparation}

Rammed clay was prepared from one type of clay - illitic clay. The recipe contained different ratios of clay and sand. The sand was used as a filler of the resulting mixture and clay served as a binder. The amount of clay was present in mixtures from 20 to $30 \%$ of the total weight of clay and sand. Reciprocally, the amount of sand was supplemented to $100 \%$ by weight, that is 70 to $80 \%$. The composition of clay and sand is shown in Table 1 .

Table 1. Tested earth compositions.

\begin{tabular}{|c|c|c|c|}
\hline Set & Signification & Clay & Sand \\
\hline 1 & AGL9 & 20 & 80 \\
\hline 2 & AGL11 & 25 & 75 \\
\hline 3 & AGL12 & 30 & 70 \\
\hline
\end{tabular}

The amount of mixing water was determined by weight against the amount of clay. Mixture 1 contained $0.45 \%$ water. Mix No. 2 had a water content of 0.4 and in the last Mix No. 3 the amount of water was 0.295 by weight of clay. All mixtures were made using river sand with a grain size of $0-2 \mathrm{~mm}$ with a continuous grain size line. The shrinkage and creep of the rammed clay was measured experimentally on special bodies. The length of the samples was $70 \mathrm{~mm}$, see Fig.2. The cross-section of the specimens was octagonal so that the bodies could be placed in the measuring device. The distance between the two opposite edges of the base corresponded to a length of $20 \mathrm{~mm}$.

The preparation of the mixture proceeded in such a way that the wet sand was mixed with half the amount of clay. The mixture was then mixed. The next step was to add the remaining amount of clay and mix. The remaining amount of water was added to the mixture during mixing. The mixture was then kneaded by hand. Finally, the mixture was again mixed with a mixer.

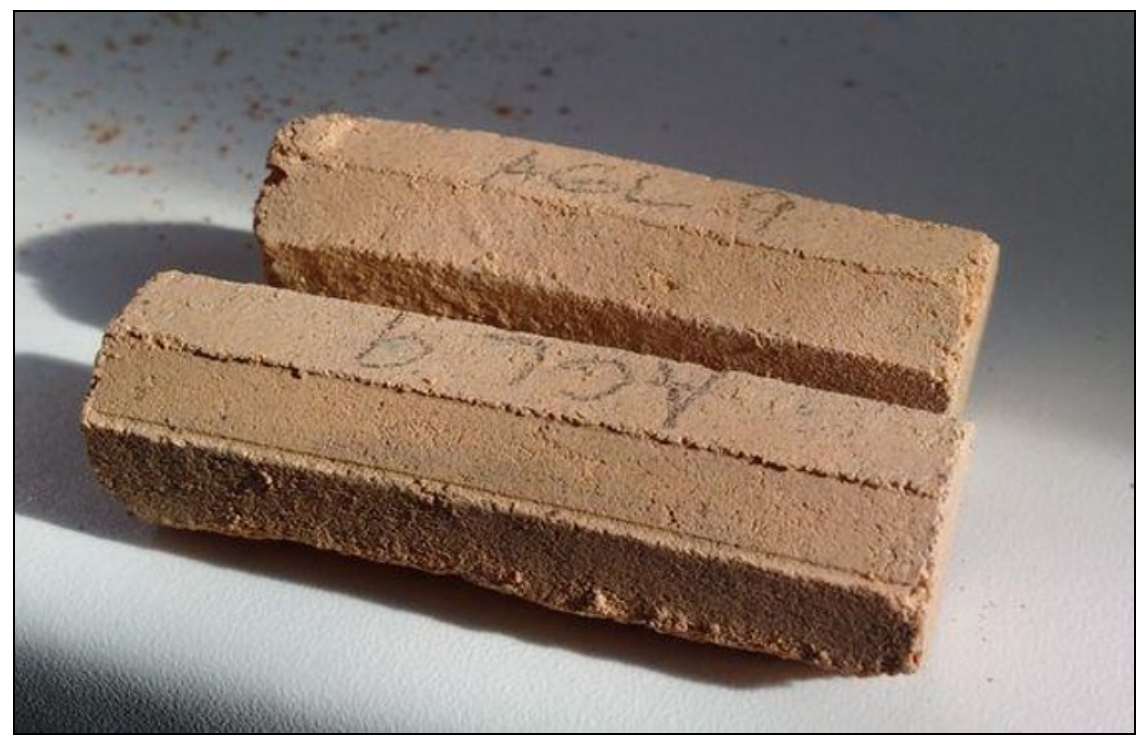

Fig. 2. Shape of specimens prepared for testing of creep and shrinkage. Label 1 wit content $20 \%$ of clay to whole weight of sand and clay. 
The mixture was deposited in molds in layers. The specimens were removed from the molds after fabrication. Immediate placement of the bodies into the measuring device followed.

\section{Measurement of creep}

Creep was measured in the lever mechanism. The body is surrounded by 3 optoelectronic sensors, which measure the axial deformation of the body. The measuring length of the sensors is the entire body height, ie $70 \mathrm{~mm}$.

6 specimens were used in each set. 3 samples were determined for creep measurement under load defined by force. The remaining three bodies were designed for shrinkage measurements.

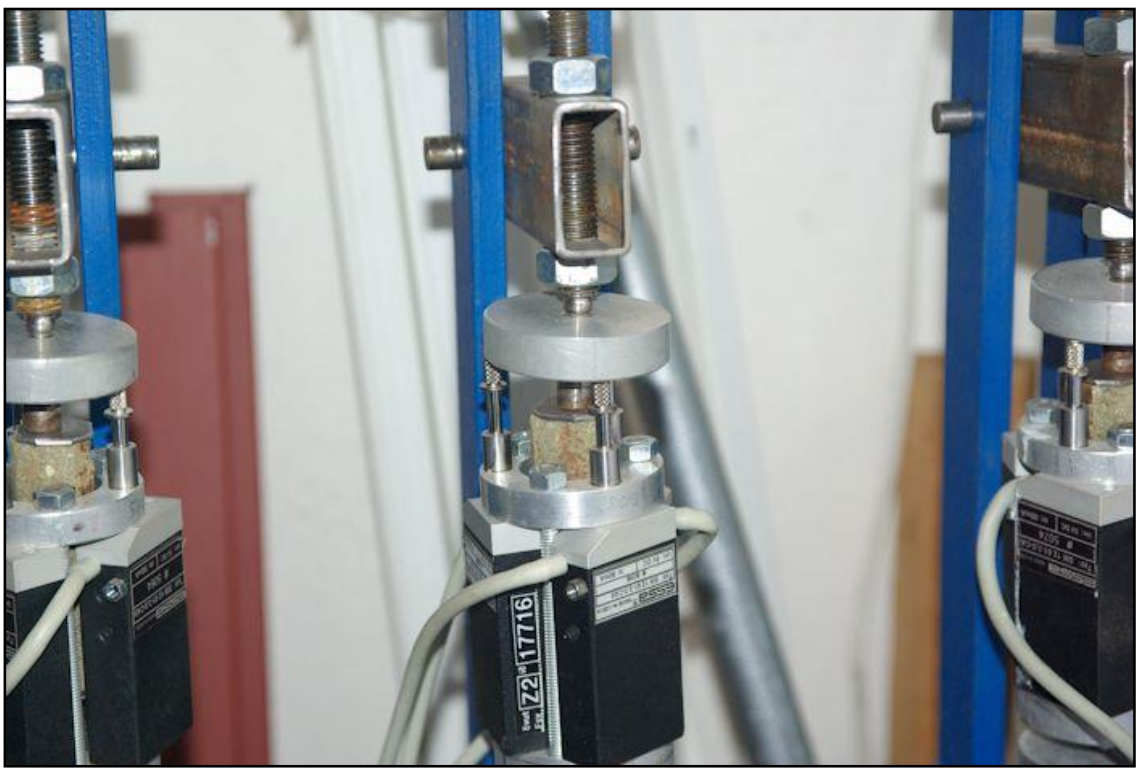

Fig. 3. Lever mechanism for creep measurement with placed rammed earth specimens.

The measurement was carried out at a steady temperature and at recorded humidity. The weight loss of the bodies in the measurement area during the test was recorded.
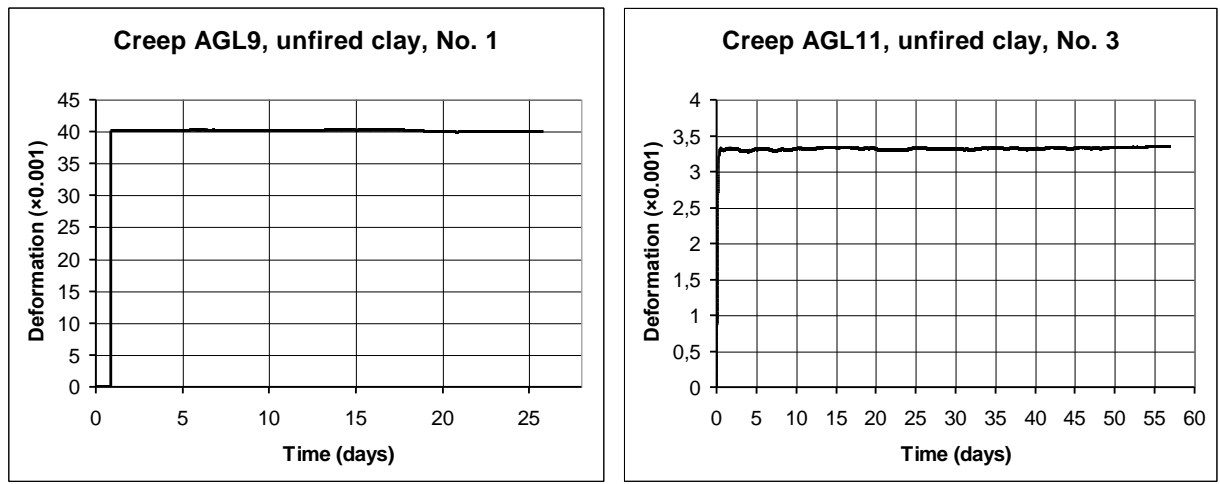

Fig. 4. Creep of rammed earth (including shrinkage) of mixture $1^{\text {st }}$ and $2^{\text {nd }}$ sets. 


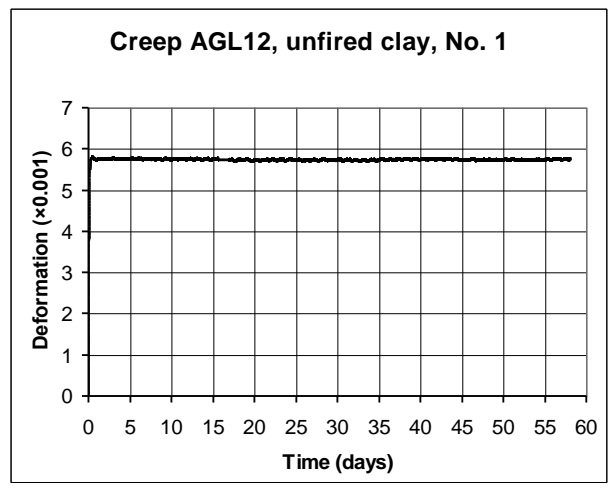

Fig. 5. Creep of rammed earth (including shrinkage) of mixture $3^{\text {rd }}$ set.

The graphs in Fig. 4 and 5 represent the typical shapes and values of the creep curves of the test materials. As can be seen from the highest creep values, the first mixture contained 0.45 water relative to clay weight. Although mixture 1 had the lowest clay content, the highest creep value corresponds to the highest water content.

Mixture 2, which contained less water than Mixture 1, and also higher clay content, had the lowest creep values. The last mixture contained the lowest amount of water and the highest amount of clay. The shape of this mixture was higher than that of mixture 2 and less than that of the set1.
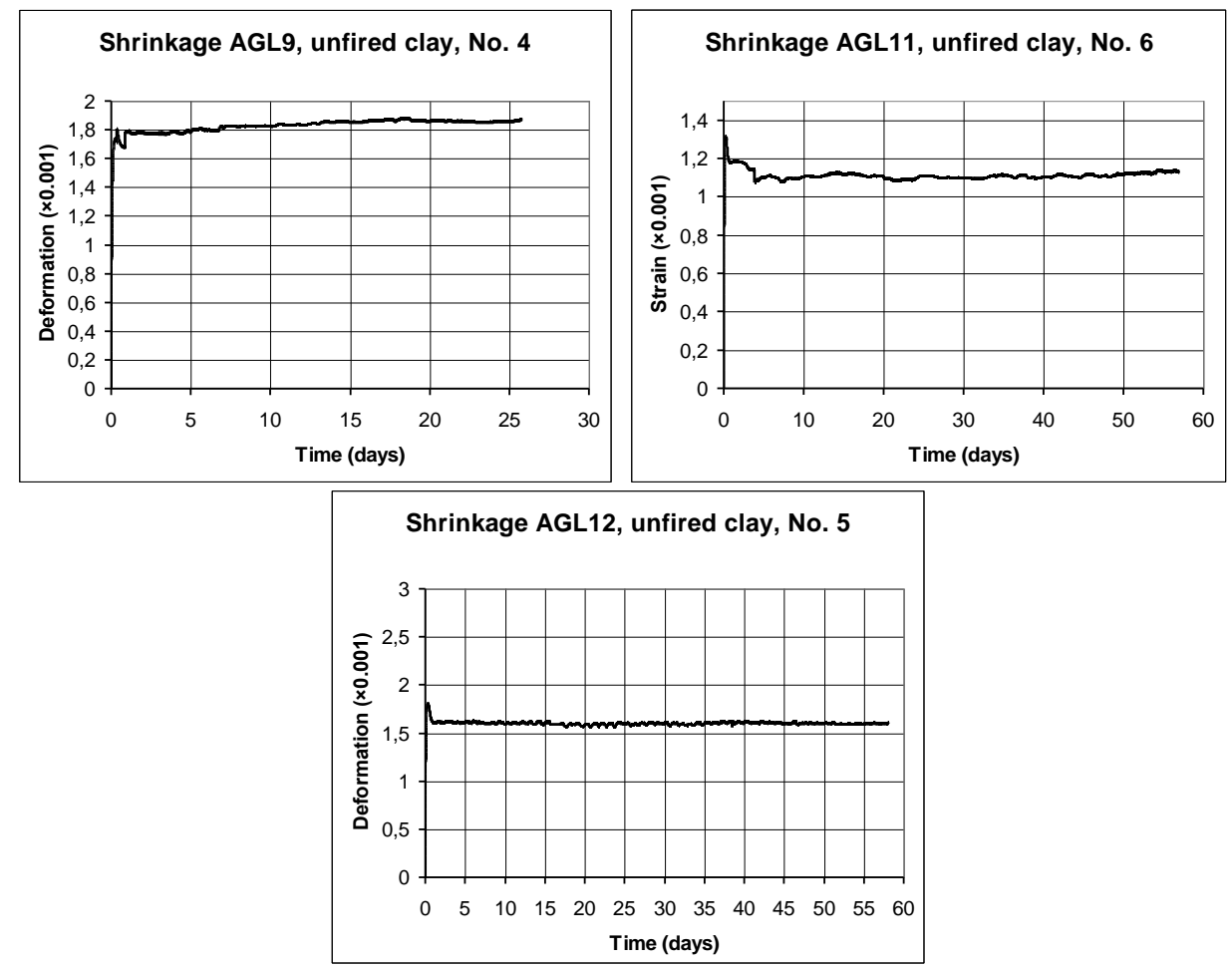

Fig. 6. Shrinkage of rammed earth of all mixtures sets. 
The view of the shrinkage of rammed earth prepared from illitic clay is also very interesting. The highest value of shrinkage was achieved by mixture No. 1 with the highest water content, see Fig.6 [6]. The second highest value of shrinkage was achieved by mixture No. 3 with the highest clay content. The lowest value was obtained from mixture 2 , which contained $25 \%$ clay of the total weight of the dry mixture and the amount of mixing water corresponded to $40 \%$ clay.

However, the shrinkage values of the three mixtures are very similar. During testing, the greatest shrinkage changes occur within the first 5 days as is possible see in Fig.7.

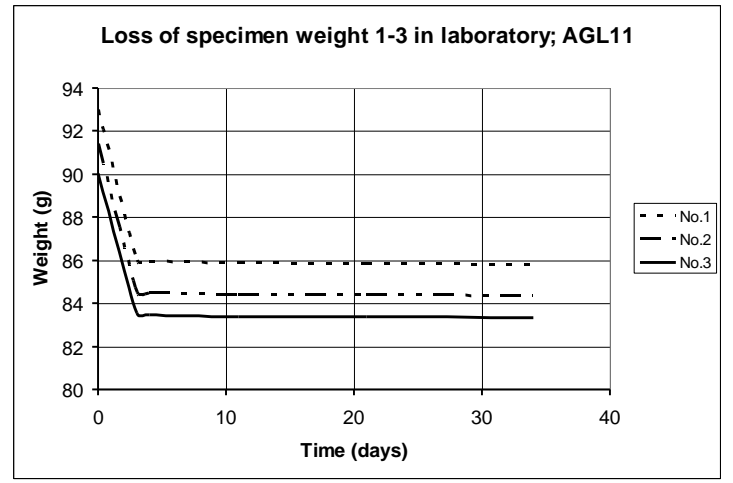

Fig. 7. Loss of weight during the test of set No.2.

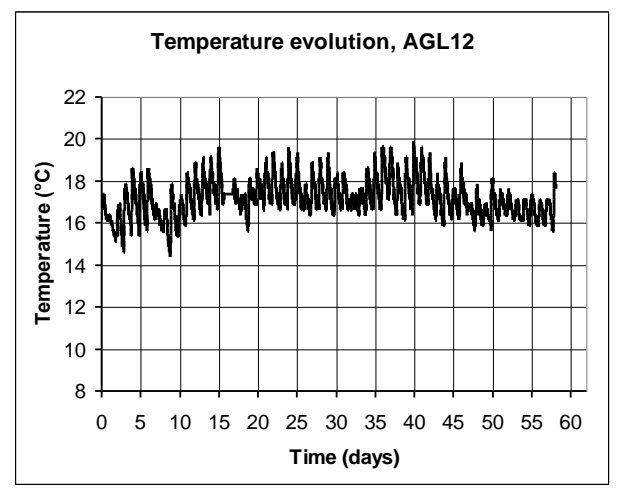

Fig. 8. Evolution of temperature during testing of rheological properties, set No.3.

\section{Discussion}

The ambient temperature of the test specimens varied within $\pm 1^{\circ} \mathrm{C}$ during the experiment, see Fig.8. Creep and shrinkage react to temperature changes, which is visible on all presented graphs. This can be seen very well in the third graph in Fig. 6. Temperature changes cause the curve to curl [7].

However, a very important factor for the creep and shrinkage size is the moisture content and gradual drying of the material. By comparing Figs. 6 and 7, it can be concluded that the greatest changes occur during the drying of the material. When drying is complete, creep and shrinkage will almost stop. $20 \mathrm{~mm}$ wide specimens took 5 days to dry. This can be seen in Fig. 7. The second graph in Figure 6 shows that major shrinkage changes also occurred during the first five days. 
All values of deformation changes are expressed in the graphs as relative values to the initial length of unloaded specimens. As can be seen, shrinkage can play an important role in the creep size. In case of set 2 (AGL11), the shrinkage is even $50 \%$ of the creep value. Conversely, the shrinkage is only $5 \%$ of the creep value for the first set. For the third set, the creep is 4 times higher than the shrinkage. The amount of clay and mixing water then determines the behaviour of the rammed earth during drying. The load size plays a very important role in the creep size. For example, setl contained a significant amount of water. There was a large increase in deformation during loading and drying.

The amount of clay also causes a significant increase in creep size. This is evident in the third set (AGL12). The mixture had a low water content, but the amount of clay in the mixture was the highest.

This research was supported by project Grant Agency of Czech Republic GACR No. 18 - 10884S "Unfired and rammed clay for construction".

\section{References}

1. I. Žabičková, Clay buildings [online], Brno, Era 21, 2002 (2015)

2. G. Minke, Building With Earth [online]. 2006, (published August 18, 2015).

3. B. Mužíková, T. Plaček Otcovská, P. Padevět, 9th annual conference Nano\&Macro Mechanics NMM2018 (2018).

4. H. Schroeder, Informes de la Constructión, 63 (523) 2011

5. P. Padevět, T. Otcovská, B. Mužíková, WSEAS Transaction on Applied And Theoretical Mechanics, 132018

6. P. Padevět, P. Bittnar, T. Otcovská, 56th International Scientific Conference on Experimental Stress Analysis EAN 2018, 2018

7. M. Jankula, T. Hulan, I. Śtubňa, J. Ondruška, R. Podoba, P. Šín, P. Bačik, A. Trnik, Journal of the Ceramic Society of Japan, 123 (1441) 2015 